\title{
Nine years' trend of dental caries and severe early childhood caries among 3-6-year-old children in Babol, Northern Iran
}

\author{
Mohammad Mehdi Naghibi Sistani ${ }^{1}$, Zohreh Hataminia ${ }^{2}$, Mahmoud Hajiahmadi ${ }^{3}$, Effat Khodadadi ${ }^{4}$
}

${ }^{1}$ Ph.D. of Community Health, Assistant Professor, Department of Community Oral Health, Faculty of Dentistry, Babol University of Medical Science, Babol, Iran

${ }^{2}$ Student Research Committee, Babol University of Medical Science, Babol, Iran

${ }^{3}$ M.Sc. of Statistics, Health Research Institute, Babol University of Medical Science, Babol, Iran

${ }^{4} \mathrm{Ph} . D$. of Pediatric, Assistant Professor, Department of Pediatrics, Faculty of Dentistry Babol University of Medical Science, Babol, Iran

\section{Type of article: Original}

\begin{abstract}
Background and objective: Malnutrition, pain, and insomnia are common adverse effects of early dental caries among 3-6-year-old children. To increase our understanding of the dental caries status which will help in the control and prevention of it, this study aimed to assess the trend of dental caries, Severe Early Childhood Caries (S-ECC) and its related factors among 3-6-year-old children during a 9-year period in Babol, Northern Iran.

Methods: This was a cross-sectional study among 2,080 children aged 3-6 years old in Babol, Northern Iran. The studied samples were examined from May 2007 to June 2015. Oral examinations were performed with visualtouch technique. S-ECC was measured as number of decayed, missing, and filled teeth surface (dmfs). Data were evaluated by SPSS software for Windows version 23 and were analyzed using the one-way ANOVA, chi-square test and independent-samples t-test. Level of significance was set at $\leq 0.05$.

Results: The trend of dental caries and S-ECC rose among 3-6-year-old children over a 9-year period. Of the children, $26.3 \%$ were caries free. The mean $\mathrm{dmft}$ was increased significantly among boys $(\mathrm{p}<0.001)$, among $3-4-$ year-old children $(\mathrm{p}=0.01)$, and those children with both employed parents $(\mathrm{p}=0.01)$ and low educated parents $(\mathrm{p}<0.001)$ from 2007 to 2015.

Conclusion: Dental caries status showed an increasing trend over the study period in Babol preschool children, therefore effective preventive strategies are required to decrease the prevalence of dental caries in children.

Keywords: Dental caries, Preschool children, Trend, Iran
\end{abstract}

\section{Introduction}

One of the most common chronic infectious diseases in childhood, especially in developing countries, is dental caries $(1,2)$. Early childhood caries (ECC) is defined as the presence of one or more decayed (noncavitated or cavitated lesions), missing (due to caries), or filled tooth surfaces in any primary tooth in a child 71 months of age or younger (3), severe early childhood caries (S-ECC) in children of age 3 to 6 years is defined as one or more cavitated, missing (due to caries), or filled smooth surface in primary maxillary anterior teeth (3). Primary dentition development completes at the age of 3 years while the first permanent tooth erupts at 6 . This age group 3-6 years may display dental caries changes over a shorter period than in the permanent dentition at other age groups (4). In addition, dental caries' status of deciduous teeth may predict the lifelong dental health status. Dental caries cause multiple complications to children's health such as pain, abscesses, loss of appetite and inability to eat, as well as significant economic burden to families and the health care system (5-7), therefore, detection of early childhood caries and screening high risk groups at longitudinal studies are pivotal (8). Preschool children showed low caries prevalence and severity in developed countries (9). In Britain, caries experience reduced to half among 5-year-old

\section{Corresponding author:}

Assistant Professor Dr. Effat Khodadadi, Department of Pediatrics, Faculty of Dentistry Babol University of Medical Science, Babol, Iran. Tel: +98. 32291093, Fax: +98. 32291408-9, Email: dr_ekhodadadi@yahoo.com

Received: January 08, 2017, Accepted: March 18, 2017, Published: June 2017

iThenticate screening: February 27, 2017, English editing: April 26, 2017, Quality control: May 14, 2017

(C) 2017 The Authors. This is an open access article under the terms of the Creative Commons Attribution-NonCommercialNoDerivs License, which permits use and distribution in any medium, provided the original work is properly cited, the use is non-commercial and no modifications or adaptations are made. 
children from 1973-83 and this reduction trend improved slightly in later years until 1999 (10). Van et al. (1) also reported that prevalence of dental caries among 12-year-old children was decreased from 1982-2002 in South Africa. In contrast, the dental caries trend is rising in developing countries $(11,12)$, Besseling et al. (13) indicated high burden of dental caries among 5-12-year-old children in Vientiane, Laos. In India, the severity and prevalence of dental caries has been increased systematically over the last five decades, and more than around two thirds of children are suffering from dental caries (14). Do et al. (15) also indicated higher caries experience among 5-10year-old children in a developing country compared with a developed country over a three-year period. In Iran, disability adjusted life years (DALYs) caused by dental caries, increased $52 \%$ at all ages, which demonstrates an upward trend during the 20-year survey (16). Shoaee et al. (16) also reported that the burden of dental caries among Iranian children under 5 years old had increased from 1990-2010. These inappropriate trends may fall short of the WHO goal of $90 \%$ caries-free among 6-year-old children by 2020 (17). Similarly, Nematollahi et al. (18) had reported more than two-thirds of all 2-6-year-old children in Birjand were affected by dental decay in 2008. Hematyar et al. (19) also reported that $63.5 \%$ of 3-7-year-old children had dental caries in Tehran in 2009. A crosssectional study in 2011 revealed that $65.6 \%$ of 3-6- year-old children had dental caries in Babol (20), however, no data on childhood dental caries have existed at different cross section times during the last decade in Babol. While, Babol University of Medical sciences' school of dentistry's autonomy from provincial centers has greater sources for oral health promotion programs, no trend study exists to reveal the impact of previous local preventive strategies and interventions on childhood dental caries. Therefore, this study aimed to assess the trend of dental caries, S-ECC and its related factors among 3-6 - year-old children from 2007-2015 in Babol, Northern Iran.

\section{Material and Methods}

This was a cross-sectional study of dental caries and S-ECC among 3-6-year-old children from May 2007 to June 2015 in Babol, Northern Iran. We used 2,080 registered documents of 3-6-year-old preschool children. These files were completed by a group of 10 senior dental students each year. In order to insure the uniformity of data collection, these examiners were trained and calibrated as an educational course at the Department of Community Oral Health, Faculty of Dentistry, Babol University of Medical Sciences. The Inter-examiner and Intra-examiner agreement was $80-85 \%$ for each group of students. Students attended 4 or 5 kindergartens randomly each year. In total,, 38 (one-third) of all 103 kindergartens were included in this study. For analysis purposes, those under 3 years and older than 6 years, as well as incomplete data and invalid files were excluded. The following instruments and supplies were used for each examiner: plane mouth mirrors, WHO standard probe (4), rubber gloves, gauze, and paper hand towels. Children were examined while seated in the class chair. Dental students measured dmft index through oral examinations using visual-touch technique and WHO standard probe (4).

The index of dmft comprised as:

- "d (decayed tooth) when a lesion in a pit or fissure, or on a smooth tooth surface, has an unmistakable cavity, undermined enamel, or a detectably softened floor or wall"

- " $m$ (missing tooth due to caries) primary teeth that have been extracted because of caries"

- "f (filled tooth due to caries) when it has permanent restorations" based on World Health Organization (WHO) guidelines (4).

The sum of $d, m$, and $f$ for each subject recorded as dmft, the sum of teeth surface with $d, m$, and $f$ for each subject recorded as dmfs. Caries free was measured as $\mathrm{dmft}=0$. For the analysis, the highest and lowest prevalent decayed tooth was recorded. Demographic data was acquired comprising of children's age, gender, education level and occupational status of their parents. Level of parents' education was measured as low: both parents had lower diploma graduation, medium: one or both parents had a diploma, and high: one or both parents had higher diploma graduation. The dmft index reveals multiple aspects of dental health such as untreated caries status, use of dental care services and families' neglect. While, mothers supervise children's dental hygiene more than fathers do, the use of dental care services depends more on fathers' decisions. Therefore, both parents educational level has important effect on children's oral health status. We analyzed all data using chi-square test, independent-samples t-test and one-way Anova with SPSS software for Windows (version 23). Level of Significance was set at $\leq 0.05$. For ethical considerations, permission for the examination of the children was received from the Bioethics Committee with grant number MUBABOL. REC.1395.113. Participation was voluntary; however, families were made aware of the duration of the examination, and their satisfaction was obtained by the manager of kindergarten.

\section{Results}

A total of 2,080 children aged 3-6 years old with mean age of 5.01 \pm 0.95 years were evaluated from May 2007 to June 2015 in Babol, Northern Iran. Table 1 presents the description of study sample characteristics, based on age, gender, parental education level and their occupational status. The total mean dmft index was $4.01( \pm 3.89)$. The 
mean dmft in boys and girls was $3.98( \pm 3.79)$ and 4.05( \pm 4.02$)$, respectively $(\mathrm{p}=0.66)$. In total, 26.3 percent $(546$ children) were caries free; $43 \%$ of 3-4-year-olds, $24.7 \%$ of 4-5-year-olds and $17 \%$ of 5-6 year-old children were caries free. In all groups, mean $\mathrm{dmft}, \mathrm{d}, \mathrm{m}$ and $\mathrm{f}$ increased with age $(\mathrm{p}<0.001)$. The mean $\mathrm{d}(\mathrm{p}=0.02)$ and $\mathrm{dmft}$ $(\mathrm{p}=0.01)$ was increased among 3-4 -year-old children from 2007-2010 to 2011-2015, (Table 2). Of the boys, mean $\mathrm{dmft}(\mathrm{p}<0.001)$, the mean $\mathrm{d}(\mathrm{p}=0.015)$ and the mean $\mathrm{f}(\mathrm{p}=0.002)$ was increased significantly from 2007-2010 to 2011-2015, however the increment in mean $\mathrm{d}$, $\mathrm{dmft}$ was not statistically significant among girls $(\mathrm{p}=0.19)$. The mean $\mathrm{d}$ and $\mathrm{dmft}$ were significantly higher in those children whose parents were both employed than one employed parent during 2007-2015 (Table 3). Also the mean d, m, and dmft was significantly higher among children with lower educated parents than other groups from 2007-2015 (Table 3). Figure 1 displays the prevalence of S-ECC among 36 -year-old children. The most decayed tooth was mandibular left first molar deciduous teeth, and the least decayed was the mandibular first primary incisor.

Table 1. Study sample characteristics among 3-6-year-old children from 2007-2015 in Babol, Northern Iran $(\mathrm{n}=2080)$.

\begin{tabular}{|l|l|l|l|l|l|l|l|}
\hline \multirow{2}{*}{ Variables } & \multicolumn{2}{|l|}{$2007-2010$} & $2011-2015$ & \multicolumn{2}{l|}{ Total } \\
\cline { 3 - 9 } & Male & 711 & 34.2 & 400 & 19.2 & 1111 & 53.4 \\
\hline \multirow{3}{*}{ Gender } & Female & 632 & 30.4 & 337 & 16.2 & 969 & 46.6 \\
\cline { 2 - 8 } & Total & 1343 & 64.5 & 737 & 35.5 & 2080 & 100.0 \\
\hline Age (year) & $3-4$ & 374 & 18.0 & 174 & 8.3 & 548 & 26.3 \\
\cline { 2 - 8 } & $4-5$ & 519 & 25.0 & 224 & 10.8 & 743 & 35.7 \\
\cline { 2 - 8 } & $5-6$ & 450 & 21.6 & 339 & 16.2 & 789 & 37.9 \\
\hline Parent's education level & Low & 96 & 5.7 & 34 & 2.0 & 130 & 6.3 \\
\cline { 2 - 8 } & Middle & 325 & 19.5 & 169 & 10.1 & 494 & 23.8 \\
\cline { 2 - 8 } & High & 596 & 35.8 & 445 & 26.7 & 1041 & 50.0 \\
\hline Parent's job status & Both employed & 1020 & 49.0 & 515 & 24.7 & 1535 & 73.8 \\
\cline { 2 - 8 } & One employed & 323 & 15.6 & 222 & 10.6 & 545 & 26.2 \\
\hline
\end{tabular}

Table 2. Mean decay, missing, fillings and dmft according to age among 3-6-year-old children from 2007-2015 in Babol, Northern Iran $(\mathrm{n}=2080)$

\begin{tabular}{|c|c|c|c|c|c|c|c|c|}
\hline \multirow[t]{2}{*}{$\begin{array}{l}\text { Age } \\
\text { (year) }\end{array}$} & \multicolumn{4}{|l|}{$\begin{array}{l}2007-2010 \\
\text { Mean } \pm \text { SD }\end{array}$} & \multicolumn{4}{|l|}{$\begin{array}{l}2010-2015 \\
\text { Mean } \pm \text { SD }\end{array}$} \\
\hline & $\mathrm{d}$ & $\mathrm{m}$ & $\mathrm{f}$ & $\mathrm{dmft}$ & $\mathrm{d}$ & $\mathrm{m}$ & $\mathrm{f}$ & $\mathrm{dmft}$ \\
\hline $3-4$ & $2.21 \pm 3.16^{\mathrm{a}}$ & $0.06 \pm 0.53$ & $0.10 \pm 0.54$ & $2.35 \pm 3.20^{b}$ & $2.89 \pm 3.37^{\mathrm{a}}$ & $0.05 \pm 0.39$ & $0.16 \pm 0.74$ & $3.10 \pm 3.44^{b}$ \\
\hline $4-5$ & $3.27 \pm 3.48$ & $0.10 \pm 0.44$ & $0.35 \pm 1.15$ & $3.71 \pm 3.63$ & $3.60 \pm 3.41$ & $0.08 \pm 0.38$ & $0.40 \pm 1.13$ & $4.08 \pm 3.73$ \\
\hline $5-6$ & $4.40 \pm 3.99$ & $0.25 \pm 0.71$ & $0.48 \pm 1.19$ & $5.12 \pm 4.12$ & $4.34 \pm 3.75$ & $0.36 \pm 1.00$ & $0.58 \pm 1.38$ & $5.28 \pm 4.16$ \\
\hline$p$-value & $<0.001$ & $<0.001$ & $<0.001$ & $<0.001$ & $<0.001$ & $<0.001$ & $<0.001$ & $<0.001$ \\
\hline
\end{tabular}

a) Significant difference of mean d among 3-4-year-old children from 2007-2010 to 2011-2015; b) Significant difference of mean dmft among 3-4-year-old children from 2007-2010 to 2011-2015.

Table 3. The mean decay, missing, fillings and dmft to parent's job and education among 3-6-year-old children from 2007-2015 in Babol, Northern Iran ( $\mathrm{n}=2080)$.

\begin{tabular}{|l|l|l|l|l|l|}
\hline \multicolumn{2}{|l|}{ Variable } & \multicolumn{4}{l|}{ Mean \pm SD (years 2007-2015) } \\
\cline { 3 - 7 } \multicolumn{2}{|c|}{} & $\mathrm{d}$ & $\mathrm{m}$ & $\mathrm{f}$ & $\mathrm{dmft}$ \\
\hline Parent 's job status & both employed & $3.63 \pm 3.71$ & $0.17 \pm 0.68$ & $0.34 \pm 1.09$ & $4.14 \pm 3.93$ \\
\cline { 2 - 6 } & One employed & $3.15 \pm 3.48$ & $0.13 \pm 0.50$ & $0.40 \pm 1.14$ & $3.67 \pm 3.77$ \\
\cline { 2 - 6 } & $p$ value & $0.009^{\mathrm{a}}$ & $0.175^{\mathrm{a}}$ & $0.258^{\mathrm{a}}$ & $0.016^{\mathrm{a}}$ \\
\hline \multirow{3}{*}{$\begin{array}{l}\text { Parent 's education } \\
\text { level }\end{array}$} & Low & $4.93 \pm 4.29$ & $0.25 \pm 0.73$ & $0.19 \pm 0.64$ & $5.36 \pm 4.41$ \\
\cline { 2 - 6 } & middle & $3.75 \pm 3.78$ & $0.15 \pm 0.57$ & $0.24 \pm 0.87$ & $4.13 \pm 3.96$ \\
\cline { 2 - 6 } & high & $3.15 \pm 3.41$ & $0.13 \pm 0.53$ & $0.44 \pm 0.23$ & $3.71 \pm 3.72$ \\
\cline { 2 - 6 } & P value & $0.000^{\mathrm{b}}$ & $0.09^{\mathrm{b}}$ & $0.001^{\mathrm{b}}$ & $0.000^{\mathrm{b}}$ \\
\hline
\end{tabular}

a) By Independent-samples t-test; b) By One way ANOVA 


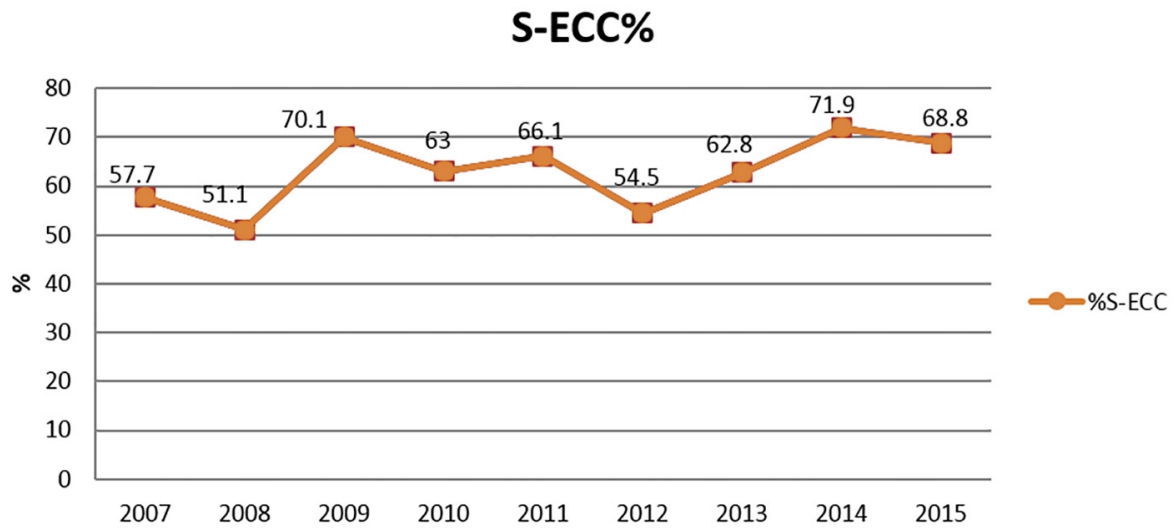

Figure 1. Trend of S-ECC among 3-6-year-old children from 2007-2015 in Babol, Northern Iran ( $\mathrm{n}=2080)$.

\section{Discussion}

The present study was conducted to assess the trend of dental caries, S-ECC and its related factors among 3-6 -yearold preschool children from 2007-2015 in Babol, Northern Iran. While, the mean dmft index of the studied sample was 4.01, the decayed component was the major part of dmft score as well. Consistent with previous findings (1922), the prevalence of dental caries was evident among more than two thirds of our studied children, which is unfortunately far from the WHO global goal of $90 \%$ caries free in 5-6-year--old children by 2020 (17).This result indicates a high rate of tooth decay and inappropriate attitude and supervision of parents regarding decayed deciduous teeth, which may have several reasons such as lack of oral hygiene practices, high cost of dental treatment, and limited accessibility of dental services (1). Similar to previous findings from developing countries (8, 14), study results confirm that the prevalence and severity of dental caries among 3-6 year-old children have increased during a 9-year period. Capurro et al. (23), however, reported a decline in the trend of untreated caries among 2-12 year-old children in the United States, which may result from available dental health insurance, therefore, dental public health insurance programs are recommended for improving access to dental care services (18). In the present study, the mean dmft of 5-6-year-olds was statistically higher than 3-4- year-old and 4-5-yearold children during a 9-year period. A similar trend was observed in a national pathfinder survey of Iranian children in 2004 (24), as well as previous results from Tehran, Varamin, and Birjand $(18,19.21)$. This may be due to increased exposure to cariogenic factors, however, poor oral hygiene (8), and absence of effective oral health preventive interventions may intensify children's dental decay status. Compared to other groups, the mean $\mathrm{d}$, dmft of only 3-4-year-oldchildren in this study significantly increased from 2007-2010 to 2011-2015. This increment was not significant in other groups. This result makes evident the lack of parents' awareness or parents' inappropriate supervision about dental health of their children, and lack of supportive oral preventive services in private health among this age group. We found dental caries increased significantly among boys over the 9 -year period. This may be due to boys being less conscious about their diet, hygiene and oral health behavior than girls, therefore, boys should be considered as a high-risk group in future health education programs. Considering this trend from another angle, fillings index of boys increased from 2011-2015 compared to 2007-2010, while the fillings index of girls decreased during the same period, however, both results were non-significant. The increased prevalence of boy's fillings may display a cultural preference for sons in Babol. According to this study, the mean $\mathrm{d}$, $\mathrm{dmft}$ were higher in children with both employed parents than children with one employed parent. Although, employment of both parents may enhance the level of family income, it was ineffective on reducing risk of dental caries in our study sample. This is probably with neglect of children's dental health care and lack of supervision about the correct nutrition pattern through busier employed parents (19). Consistent with earlier findings $(8,18,25)$, the mean $\mathrm{d}$, $\mathrm{m}$, and $\mathrm{dmft}$ of our studied children with less educated parents increased from 2007-2015. While parents play an important role in the prevention of children's dental caries, authorities should provide programs to improve oral health care knowledge and awareness, especially among parents with low education levels. Poor oral hygiene, lack of access to dental care and lack of parental attention to children's dental health leads to S-ECC (26). The present study trend revealed an increasing pattern in the trend of S-ECC, distinctly two-thirds of the 3-6-year-old children had S-ECC in 2015. This trend decreased between 2007 to 2008 and 2011 to 2012, however, this decline was nonsignificant and may result from lower sample size. Similarly, Nematollahi et al. (18) reported that 50.2\% of 3-6year-old children had SECC in Birjand in 2006. Bagherian et al. (27) reported that 51.2\% of same age children had SECC in Rafsanjan in 2007. According to the result, the most susceptible tooth to caries was the mandibular left first 
molar deciduous teeth, and the most resistant tooth to caries was primary mandibular left incisor. In our study, the posterior region was more commonly affected by caries than the anterior region. This is in agreement with the study of Bayat-movahed (24) and Agarwal et al. (11). This may be due to the complex morphological nature of posterior teeth and more protection of the anterior mandibular teeth with saliva flow (3). It seems, implementing some strategies such as providing free services and insurance could be indispensable to protect primary posterior teeth. This study is limited to multiple examiners who were calibrated in the Department of Community Oral Health. However, this is the first attempt to study a great sample of children over a nine-year period. Because of the multi factorial feature of dental caries, future studies are recommended to provide evaluation of other important and effective factors on dental caries such as: frequency of sweet feeding during the day, tooth brushing regularity, breast feeding duration, systemic and gingival disease.

\section{Conclusions}

The prevalence of dental caries and S-ECC increased among 3-6-year-old children from May 2007 to June 2015 in Babol, Northern Iran. These results indicated that boys, 3-4-year-old children, and children who have low educated parents or both their parents were employed, were the high-risk groups to more dental caries. Therefore, early detection and effective preventive strategies are recommended to decrease the prevalence of dental caries. Babol University of Medical Sciences should provide more effort to prevent dental caries in different settings such as health sectors and kindergartens, especially among families with low social level.

\section{Acknowledgments:}

This research was supported by Babol University of Medical Science and Health Services grant number MUBABOL.REC.1395.113. The authors wish to thank Babol Welfare Organization, the kindergarten's managers, the nurse of the Department of Community Oral Health and the Statistical Consulting Partner. This study was part of an undergraduate dental student thesis.

\section{Conflict of Interest:}

There is no conflict of interest to be declared.

\section{Authors' contributions:}

All authors contributed to this project and article equally. All authors read and approved the final manuscript.

\section{References:}

1) van Wyk C, van Wyk PJ. Trends in dental caries prevalence, severity and unmet treatment need levels in South Africa between 1983 and 2002. SADJ. 2010; 65(7): 310, 2-4. PMID: 21133233.

2) Campus G, Sacco G, Cagetti M, Abati S. Changing trend of caries from 1989 to 2004 among 12-year old Sardinian children. BMC public health. 2007; 7: 28. doi: 10.1186/1471-2458-7-28. PMID: 17331258, PMCID: PMC1832181.

3) Mc Donald RE, Avery DR, Weddell J. McDonald and Avery Dentistry for the children and adolescent. 10th ed. Saintt Louis: Mosby; 2016.

4) World Health Organization. Oral health surveys: basic methods. 4th ed. Geneva; 1997.

5) Heilmann A, Tsakos G, Watt RG. Oral Health over the Life Course. In: Burton-Jeangros C, Cullati S, Sacker A, Blane D, editors. A Life Course Perspective on Health Trajectories and Transitions. Cham $(\mathrm{CH})$ : Springer Copyright 2015, the Author(s). PMID: 27683931.

6) Moses J, Rangeeth BN, Gurunathan D. Prevalence of dental caries, socio-economic status and treatment needs among 5 to 15 year old school going children of Chidambaram. J Clin Diagn Res. 2011; 5(1): 14651.

7) Nazar H, Al-Mutawa S, Ariga J, Soparkar P, Mascarenhas AK. Caries Prevalence, Oral Hygiene, and Oral Health Habits of Kuwaiti Infants and Toddlers. Med Princ Pract. 2014; 23(2): 125-8. doi: 10.1159/000356866. PMID: 24356643.

8) T S, Kumar B S, Datta M, V T H, Nisha V A. Prevalence, Severity and Associated Factors of Dental Caries in 3-6 Year Old Children. J Clin Diagn Res. 2013; 7(8): 1789-92. doi: 10.7860/JCDR/2013/6201.3277. PMID: 24086915, PMCID: PMC3782972.

9) Brunelle JA, Carlos JP. Recent trends in dental caries in US children and the effect of water fluoridation. J Dent Res. 1990; 69 Spec No: 723-7. doi: 10.1177/00220345900690S141. PMID: 2312893.

10) Daly B, Watt GR, Batchelor P, Tresure TE. Essential Dental Public Health. Oxford University; 2003. 
11) Agarwal D, Sunitha S, Reddy CVK, Machale P. Early Childhood caries prevalence, severity and pattern in 3-6 year old preschool children of Mysore City, Karnataka. Brazilian Research in Pediatric and Integrated Clinic. 2012; 12(4): 561-5. doi: 10.4034/pboci.2012.124.18.

12) Awooda EM, Saeed SM, Elbasir E. Caries prevalence among 3-5 years old children in Khartoum state Sudan. medical and health science. 2013;3(2).

13) Besseling S, Ngonephady S, Van Wijk AJ. Pilot survey on dental health in 5-12-year-old school children in Laos. J Investig Clin Dent. 2013; 4(1): 44-8. doi: 10.1111/j.2041-1626.2012.00136.x. PMID: 23188620.

14) Shilpashree KB, Manjunath C, Ramakrishna T. Dental Caries Experience Among Children Aged 3-6 Years Attending Government Early Child Care Educational Centers of Bengaluru South, India. Journal of Dentistry and Oral Medicine. 2013; 1(2): 25-8.

15) Do LG. Distribution of caries in children: variations between and within populations. J Dent Res. 2012; 91(6): 536-43. doi: 10.1177/0022034511434355. PMID: 22223436.

16) Shoaee S, Ghasemian A, Mehrabani K, Naderimagham S, Delavari F, Sheidaei A, et al. Burden of Oral Diseases in Iran, 1990-2010: Findings from the Global Burden of Disease Study 2010. Arch Iran Med. 2015; 18(8): 486-92. doi: 015188/AIM.005. PMID: 26265516.

17) Hobdell M, Petersen PE, Clarkson J, Johnson N. Global goals for oral health 2020. Int Dent J. 2003; 53(5): 285-8. PMID: 14560802.

18) Nematollahi H, Mehrabkhani M, Esmaeili HO. Dental Caries Experience and its Relationship to SocioEconomic Factors in 2-6 year old Kindergarten Chidren in Birjand - Iran in 2007. J Mash Dent Sch. 2009; 4(32): 325-32.

19) Hematyar M, Masnavi A. Prevalence and risk factors of dental decays in 3-7 years old children referred to pediatric clinics of Islamic Azad University. The Journal of Qazvin University of Medical Sciences. 2009; 13(3): 87-94.

20) Ghasempour M, Hajian K, Moazzezi Z, Zavar M. Relationship between BMI and dental caries index in preschool children in Babol. Journal of Isfahan Dental School. 2011; 7(3): 280-7.

21) Nabipour AR, Azvar K, Zolala F, Ahmadinia H, Soltani Z. The Prevalence of Early Dental Caries and Its Contributing Factors among 3-6-Year-Old Children in Varamin/Iran. Journal of Health and Development. 2013; 2(1): 12-21.

22) Ghandahari Motlagh M, Zeraati H. Dental Health Status in 3-5 Year Old Kindergarten Children in TehranIran in 2003. Journal of Dentistry, Tehran University of Medical Sciences. 2005; 2(1): 18-20.

23) Capurro DA, Iafolla T, Kingman A, Chattopadhyay A, Garcia I. Trends in income-related inequality in untreated caries among children in the United States: findings from NHANES I, NHANES III, and NHANES 1999-2004. Community Dent Oral Epidemiol. 2015; 43(6): 500-10. doi: 10.1111/cdoe.12174. PMID: 26037290.

24) Bayat-Movahed S, Samadzadeh H, Ziyarati L, Memary N, Khosravi R, Sadr-Eshkevari PS. Oral health of Iranian children in 2004: a national pathfinder survey of dental caries and treatment needs. East Mediterr Health J. 2011; 17(3): 243-9. PMID: 21735966.

25) Khazaei M, Mahvil H, Fouladi Fard A, Izanloo R, Yavari H, Tashayoei Z. Dental Caries Prevalence among Schoolchildren in Urban and Rural Areas of Qom Province, Central Part of Iran. Middle-East Journal of Scientific Research. 2013; 18(5): 584-91.

26) Razmiene J, Vanagas G, Bendoraitiene E, Vysniauskaite A. The relation between oral hygiene skills and the prevalenceof dental caries among 4 - 6-year-old children. Stomatologija. 2011; 13(2): 62-7. PMID: 21822047.

27) Bagherian A, Sadeghi M. Association between dental caries and age-specific body mass index in preschool children of an Iranian population. Indian J Dent Res. 2013; 24(1): 66-70. doi: 10.4103/0970-9290.114956. PMID: 23852235. 